\title{
LA LUCHA CONTRA LA CORRUPCIÓN Y LA PANCRIMINALIZACIÓN DEL AUTOBLANQUEO
}

\author{
Gonzalo Quintero Olivares*
}

Resumen: En los últimos tiempos, en especial tras la reforma de 2015, raro es el escrito de acusación que, en relación con delitos con contenido de beneficio económico para sus autores, no incluya la imputación de blanqueo, normalmente referida a las modalidades de tenencia, posesión o utilización. La reflexión sobre la infracción del principio non bis in idem se ha ido extendiendo doctrinalmente y en algunos fallos judiciales aparece el rechazo a la acumulación de calificaciones. Pese a ello, se sigue sosteniendo por muchos que, en la lucha contra la corrupción no se puede prescindir de ese armamento, lo cual no es cierto. La admisibilidad del autoblanqueo ha de ser sometida a muchos condicionantes, y cuestionar severamente si ese instrumento de lucha contra la corrupción no conlleva insalvables contradicciones penales. En la misma línea crítica se han de incluir las extensiones de la imputación

Recibido: octubre 2017. Aceptado: junio 2018

* Catedrático de Derecho Penal.

Departamento de Derecho Público. Facultad de Ciencias Jurídicas de la Universidad Rovira i Vigili, Avda. Catalunya, 35, 43002, Tarragona. Email: gonzalo.quintero@urv.cat 
de blanqueo a terceras personas que, por la razón que sea, participan en la utilización por parte de los autores del delito.

Palabras clave: corrupción, blanqueo de capitales, non bis in idem.

\section{THE FIGHT AGAINST THE CORRUPTION AND THE TOTAL CRIMINALIZATION OF THE SELF-LAUNDERING}

Abstract: Over the past few years it is not uncommon to find a prosecution indictment relating economic crimes, which includes charges for money laundering (normally associated with the modalities of holding, possessing, and using money). Based on the ne bis in idem principle a number of judicial decisions have rejected the accumulation of qualifications. It is necessary to examine the compatiblity of the so called "self-laundering" with the basic principles of criminal law. The same applies to all individuals who engage, directly or indirectly, in the use of money by the author.

Keywords: corruption, money laundering, non bis in idem

\section{La persecución indirecta de la corrupción, en especial a través del autoblanqueo}

Las páginas que siguen no están dedicadas a censurar la consideración del delito de autoblanqueo de dinero, como delito imprescindible en la lucha contra la delincuencia organizada, la corrupción y que, además, está presente en las leyes penales de nuestro tiempo, y, según ello, es obligada en cumplimiento de mandatos internacionales de todos conocidos. Por supuesto que no pretendo criticar la incriminación del blanqueo, sin perjuicio de que su descripción técnica esté llena de problemas, como saben todos los que se han acercado a su estudio ${ }^{1}$. Mi objetivo no es ofrecer una nueva exposición teórica del delito de blanqueo, sino algo diferente y más modesto, como es la indicación de la perversión de su aplicación.

1 Sin propósito exhaustivo, I. Blanco Cordero, "El delito de blanqueo de capitales", Aranzadi, 2012; Blanco, El delito fiscal como actividad delictiva previa del blanqueo de capitales", Revista Electrónica de Ciencia Penal y Criminología, 13-01, 2011; Blanco, "Acciones socialmente adecuadas y delito de blanqueo de capitales", en Anuario de Derecho Penal y Ciencias 
Antes de proseguir, debo aclarar lo que entiendo por perversión de uso. El delito de blanqueo nació para unas finalidades político-criminales concretas: atrapar al delincuente, al que no se ha podido descubrir o detener cuando cometió los delitos, posteriormente, cuando intente o consiga introducir en el mercado el beneficio de sus delitos. Pero lo que no puede admitirse es que el delito de blanqueo sea una "sanción adicional" que se puede imponer en un sinfín de conductas delictivas. La regulación legal del blanqueo, y algunas de las interpretaciones que de ella se han hecho, hacen de esta figura uno de los mayores riesgos para el Estado de Derecho, la seguridad jurídica, la proporcionalidad y el principio non bis in idem. Cualquier calificación acusatoria va acompañada, como si de un postre natural se tratase, de la imputación de blanqueo, que es utilizada como cajón de sastre en el que se puede incluir cualquier clase de relación con un bien procedente de delito o con la persona que lo tiene.

La regulación legal del blanqueo propicia que eso suceda, pero la causa profunda no está en la existencia del delito de blanqueo, como es lógico, sino en la progresiva desvirtuación de su sentido, que comienza cuando el blanqueo abandona la condición de infracción independiente, que puede aparecer tras

Penales, 1997; E. Demetrio Crespo, "Sobre el fraude fiscal como actividad delictiva antecedente del blanqueo de dinero", Revista General de Derecho Penal, $n^{\circ}$ 15, 2011; P. Faraldo Cabana, "Antes y después de la tipificación expresa del autoblanqueo de capitales”, en Estudios Penales y Criminológicos, vol. XXXIV, 2014; Dopico Gómez Aller, "Si todo es blanqueo, nada es blanqueo", en Legaltoday.com, 15 de Enero de 2010; D. Gómez Iniesta, "El delito de Blanqueo de Capitales en derecho español", Barcelona, Cedecs, 1996; J.L. González Cussac, dir., A. Fernández, coord., "Financiación del terrorismo, blanqueo de capitales y secreto bancario", Valencia, Tirant lo Blanch, 2009; Quintero, "El delito fiscal y el ámbito material del delito de blanqueo", Actualidad Jurídica Aranzadi, n 698, febrero 2006; Quintero, "Sobre la ampliación del comiso y el blanqueo, y la incidencia en la receptación civil", Revista (e) de Ciencia Penal y Criminología, Granada, 12-r2, 2010; Quintero, "Blanqueo, comiso y tributación del dinero sucio" en Crisis financiera y derecho penal económico , BdF-Edisofer, Madrid-Buenos Aires-Montevideo, 2014; J.Zaragoza Aguado, dir."Prevención y represión del blanqueo de capitales", Estudios de Derecho judicial, 28, Consejo General del Poder Judicial, Madrid, 2000, 
la comisión de delitos generadores de bienes, pero en la que no han de intervenir los propios autores y partícipes de esos delitos.

La experiencia enseña que en ciertos tipos de criminalidad organizada, especialmente la vinculada al narcotráfico, los beneficios entran en el circuito económico normal acompañados de falsedades de toda clase, de corrupciones de funcionarios o de gestores financieros, etc. En esos casos es fácil comprender que el «proceso de blanqueo» ha supuesto la comisión de nuevos delitos, en los que también ha intervenido el responsable de los delitos anteriores (los generadores del producto).

Pero podría darse el supuesto de operaciones de blanqueo en las que la aparición de delito no fuera tan evidente, como, por ejemplo, la colocación por parte del propio responsable criminal del delito, de cantidades de dinero no «espectaculares», en multitud de cuentas corrientes o libretas de ahorro de diferentes entidades bancarias, o la compra de objetos valiosos en el mercado o en subastas, en España o en el extranjero -prescindiendo de las investigaciones sobre obligaciones tributarias emergentes o no satisfechas en otros Estados que pudieran conducir al descubrimiento del origen de ese dinero-. En esos ejemplos, de acuerdo con lo que ahora dispone el art. 301 CP habría que afirmar que de cada una de esas acciones nace un delito de blanqueo (o un delito continuado, incluso) del que será responsable el mismo sujeto que, por ejemplo, había obtenido ganancias traficando con drogas o explotando la prostitución. La transformación de esas acciones en delictivas adicionales, puede resultar excesiva.

Así las cosas puede entenderse que, a la vista de la aparente «libertad de decisión» que el mandato europeo confiere, el legislador español puede incriminar el autoblanqueo, como ha hecho, forzando gravemente la lógica interna de una figura que deriva de la receptación, y no de la coejecución o la complicidad, pero hubiera debido precisar mejor los elementos del tipo que deben concurrir cuando el autor es el propio generador del «dinero sucio». La razón es fácil de captar: cuando es un tercero el que ayuda a esa tarea la esencia de lo injusto se centra en su 
conocimiento del origen y de que está ayudando a un delincuente. Es evidente que así no se pueden configurar los elementos del «autoblanqueo punible».

No se ha hecho así, y el legislador prefirió tomar una senda que conduce a una mala disyuntiva: apreciar blanqueo en un irracional elenco de supuestos o, para evitar esa conclusión, prescindir de aplicarlo en otra amplia gama de casos, con lo cual flaco favor se hace a la pretensión de luchar contra la criminalidad organizada, que fue la causa de su nacimiento.

El olvido de ese origen es la razón última del mal uso, a lo que nuestro derecho añade, para completar el escenario, la posibilidad de imputar por blanqueo a los autores del delito previo -cierto que se hace siguiendo directrices supranacionales- sin limitación alguna, además de que constituye blanqueo la mera posesión ${ }^{2}$ y admite la comisión imprudente.

En lo que sigue intentaré exponer algunas de las desviaciones que se producen en la persecución indirecta de la corrupción a través de la aplicación de delitos que son diferentes de los propios de la corrupción, y no solo los delitos de blanqueo, sino también a través de otras figuras, como es, especialmente, el delito tributario. Tal vez el recuerdo de Al Capone, atrapado precisamente por delitos fiscales, hace tener una gran confianza en la vía del impago de impuestos.

\section{Corrupción y delito fiscal}

La relación entre lucha contra la corrupción y persecución del blanqueo del dinero es de toda evidencia y no precisa

2 Hay que tener en cuenta, sin que eso sea una excusa, que el legislador español estaba además presionado por las indicaciones de reformas necesarias para la lucha contra la corrupción y el blanqueo que había promovido la OCDE, y que exigían la incriminación directa de la tenencia injustificada de bienes. Como, con buen criterio, se estimó que eso no podía ser compatible con nuestro orden constitucional, se optó por vías indirectas como fue la de ampliar el tipo de blanqueo en la manera en que se hizo con la reforma operada a través de la Ley 5/2010. 
de mayores explicaciones. Ello, no obstante, la persecución del blanqueo se inició en el campo de los delitos relacionados con el tráfico de drogas y la criminalidad organizada (los fenómenos mafiosos). Sin perjuicio de ello, hoy se asume que el instrumento "delito de blanqueo" es imprescindible en la lucha contra la corrupción, y, precisamente por eso, el blanqueo de dinero está previsto como delito conexo en los diferentes convenios internacionales sobre lucha contra la corrupción ${ }^{3}$.

Un primer problema, orillado pese a su evidencia, es la inconcreción misma del concepto de "corrupción", que es un adjetivo común a muy diferentes modalidades delictivas, pero no privativa de un grupo preciso. Más aún: se hace continua referencia a los nuevos modos que tiene la corrupción para colarse en los más diferentes ámbitos, cual si se tratara de un gas tóxico, invisible e intangible.

Es verdad que las manifestaciones de la criminalidad que ha conocido nuestro tiempo eran inimaginables hasta hace no muchos años, y basta pensar, por ejemplo, en las "tramas" organizadas para burlar el IVA 4 . Pero el que las mutaciones sean muy frecuentes no quiere decir que los tipos de delito, puedan ir variando sus interpretaciones posibles, hasta vaciarlos de sentido, haciendo que pierdan coherencia con la norma de la que proceden.

Está fuera de duda que algunos grupos de infracciones han pasado a ocupar el primer plano en la atención ciudadana, como sucede con los delitos relativos a la corrupción, cuyas configuraciones típicas no son capaces de acoger la multiplicidad de vías de aparición del problema, y eso exige revisiones de las figuras legales, que apenas se han acometido 5 .

3 Aplicándose los mismos criterios que se siguen, en orden a la persecución de la financiación del terrorismo, de tal modo que los documentos internacionales se refieren a la vez a ambas cuestiones (terrorismo y blanqueo).

4 Ilustrativo es el trabajo de Méndez Cortegano y Pujante Gil, "Estrategia de lucha contra las tramas organizadas de fraude en el IVA intracomunitario", Instituto de Estudios Fiscales, 2007.

5 Por ejemplo: revisar la facilidad con la que en España, pese a algunos correctivos de los últimos tiempos, se puede poner en funcionamiento una 
También hay que reconocer que la tarea que tiene por delante el legislador no es fácil. Cristalizar en tipos penales todas las maniobras que se pueden hacer con el dinero procedente de delitos, es trabajo arduo, y si desde el dinero (inducción inversa) se quieren descubrir los casos de corrupción se caerá en el absurdo, pues es vana pretensión creer que retroactivamente "aparecerá" el rastro de un delito detectando los movimientos contables de personas físicas o jurídicas.

El primer peligro, que no es el único, es confundir el dinero sucio, procedente de delitos, con el dinero negro, esto es, aquel que se ha ganado sin luego cumplir con los procedimientos fiscales ortodoxos (declaración de ingresos en orden a la liquidación y pago de los impuestos), olvidando que ese dinero, que sin duda ha generado una obligación tributaria, no procede de delito alguno, salvo que dé lugar a un delito tributario. Por lo tanto, cuando esa actividad se quiere reprimir a través de las normas que castigan el blanqueo se produce una desviación de función de esas normas, concebidas para perseguir ganancias procedentes de delitos, no de un trabajo no delictivo que, simplemente, no ha tributado.

El fraude fiscal exige específicas formas de lucha, y la corrupción y la criminalidad organizada, también. Son luchas que, a buen seguro, tienen claramente muchos puntos en común, pero no deben confundirse, y eso es lo que sucede, $\mathrm{y}$, como luego veremos, es una de las razones de la "sistemática" y "cautelar" calificación de blanqueo que se aplica a toda conducta en la que medie dinero, y eso se hace sin especiales reflexiones, como si se tratara de solicitar la imposición de las costas del proceso.

Del mismo modo, y en sentido contrario, tratar al dinero "sucio" con el mismo criterio que al dinero "negro" (el no declarado), tampoco conduce a conclusiones satisfactorias. Cuando se ideó la política de persecución del blanqueo, como he dicho

sociedad anónima totalmente carente de contenido, y que puede ser un buen instrumento para actividades corruptas. 
antes, se contempló un escenario en el que el delincuente o el grupo criminal tenía que reintroducir en el mercado el dinero obtenido criminalmente, pero no se partía de que fuera a "declarar sus ganancias", idea que es, por raro que parezca, considerada como "normal", cuando la cuestión de la tributación de las rentas de origen delictivo, encierra un cúmulo de graves problemas: llegar a la conclusión de que el ladrón que ha declarado sus "ganancias", tributando por ellas, por más que haya dicho que son frutos de actividades "profesionales, artísticas o artesanales", ha legalizado, en cierta medida, el dinero que tiene, que ha dejado de ser "negro".

Precisamente eso es lo que parece repugnar a la sensibilidad jurídica, teniendo en cuenta la garantía constitucional del derecho a no declarar contra uno mismo y a no confesarse culpable, reconocido en el art. 24.2 CE. En efecto, en la medida en que la obligación de tributar por las rentas procedentes del delito supusiera la obligación de declarar su real procedencia, podría considerarse vulnerada esa garantía del art. $24 \mathrm{CE}$.

El lector dirá que, para eso, precisamente, se ha ampliado el campo de los delitos previos en el blanqueo, incluyendo al delito fiscal, pero, con independencia de las dificultades que entraña aceptar el delito fiscal como delito previo, que luego volveré sobre la cuestión, no puede llevar a buen puerto utilizar un recurso técnico y político criminal ideado para los frutos de los delitos para castigar lo que se haga con dinero no declarado $-\mathrm{y}$ no entro ahora en el problema del límite mínimo de la tipicidad del delito fiscal, que, como es lógico, condicionará la aplicabilidad del blanqueo.

La corrupción genera dinero, por supuesto, y sus protagonistas, autores de delitos como el cohecho, el fraude a la Administración, las negociaciones prohibidas, etc., tienen el correspondiente problema, que comienza $-\mathrm{y}$ ahí surge un nuevo tema debatido- con el dinero procedente de esas acciones, dinero que pese a ser negro debe tributar. La idea de que hay que apreciar delito fiscal por la falta de tributación por las rentas procedentes de delitos propios de la corrupción, puede chocar con la existencia de 
unas consecuencias punitivas propias para esos delitos, que se incrementaría con el delito fiscal y, ulteriormente, con el blanqueo.

Sin embargo, el TS afirma la existencia de obligaciones tributarias derivadas de la obtención de rentas ilícitas y la consiguiente posibilidad de apreciar el delito fiscal por la falta de declaración y satisfacción de las mismas ${ }^{6}$, negando, además, que por ello se vulnere el derecho fundamental a no declarar contra uno mismo. ${ }^{7}$

Esas tesis jurisprudenciales, no obstante, han de ser acogidas sin desviarse de los supuestos enjuiciados, pues, en los casos juzgados, no era tanto el dinero directamente procedente de la actividad corrupta, cuantos frutos ulteriores obtenidos con ella. En cambio, desde STS 20/2001, sí ha apreciado el concurso de leyes entre los delitos antecedentes y el delito fiscal, pues el hecho base sobre el que se asientan es el mismo, "cuando los incrementos patrimoniales que generan el delito fiscal proceden de modo directo e inmediato de un hecho delictivo que también

6 Ya en STS 649/1996, aceptada la procedencia ilícita del dinero, que deriva de los datos relativos a su volumen y clandestinidad con la que se gestionaba, no ve problema alguno en condenar por delito fiscal cometido con las ulteriores ganancias obtenidas con los rendimientos del dinero originariamente delictivo. El mismo criterio se aplica en STS 1493/1999: concurso de delitos entre las infracciones antecedentes (delitos continuados de cohecho, malversación, estafa y falsedades) y delitos fiscales.

7 En STS 1493/1999 rechaza también la alegación relativa a la vulneración de la interdicción constitucional a la compulsión a declarar contra uno mismo y a no confesarse culpable (art. 24.2 CE), en atención a que "las garantías frente a la autoincriminación se refieren en este contexto solamente a las contribuciones del imputado o de quien pueda razonablemente terminar siéndolo y solamente a las contribuciones que tienen un contenido directamente incriminatorio." De lo que deriva que "el temor a que la declaración fiscal, al incluir ganancias de difícil justificación o bienes adquiridos con fondos de ilícita procedencia, pueda contribuir al afloramiento de actividades ilícitas no puede configurarse como una causa privilegiada de exención de la obligación de declarar, supuestamente amparada en un derecho constitucional y de la que se beneficiarían los ciudadanos incumplidores de la ley en detrimento de los respetuosos del derecho, pues no nos encontramos ante «contribuciones de contenido directamente incriminatorio» 
es objeto de condena (con la consiguiente pérdida de los beneficios derivados del mismo por comiso o indemnización) dado que en estos concretos supuestos la condena por el delito que constituye la fuente directa e inmediata del ingreso absorbe todo el desvalor de la conducta y consume al delito fiscal derivado únicamente de la omisión de declarar los ingresos directamente procedentes de esta única fuente delictiva". 8

Expuesta así la cuestión parece convincente el razonamiento. Pero el observador no puede dejar de preguntarse si respecto de todos y cada uno de los sujetos condenados por delitos patrimoniales o económicos, se verifica si han incluido en su declaración de renta (en el supuesto de que la hayan presentado) las ganancias procedentes de delito, en orden a la derivación de responsabilidad administrativa o penal por impago del tributo.

\section{Corrupción y blanqueo}

En el apartado anterior me he referido a cómo el fruto de la corrupción puede ser la base material de un delito fiscal, salvo que la pena de los delitos de corrupción absorba a la del delito fiscal. Hemos visto, también, que el delito fiscal puede construirse sobre dinero "negro" y sobre dinero "sucio", y, por último, sabemos que el delito de blanqueo nació como arma indirecta de lucha contra la delincuencia, porque entra en juego cuando quieren introducir en el mercado los frutos de sus delitos. La inclusión del delito fiscal como antecedente, que indistintamente se puede producir con dinero "negro" o "sucio", no es coherente con el origen politico-criminal del blanqueo.

8 Lo cual no es óbice para reiterar que, en virtud del principio de igualdad tributaria no puede dispensarse un trato más favorable al infractor de la ley que ha conseguido ilícitamente el dinero, y rechaza la vulneración del art. 24 $\mathrm{CE}$, si bien se introduce un matiz: si el hecho delictivo en el que se fundamentaría la condena por delito fiscal coincide con el mismo en que se funda la condena por cohecho: la percepción de dádivas, sobre las que ya se había decretado el comiso, no puede, además, condenarse por delito fiscal, cuyo castigo es absorbido por los delitos generadores del dinero ( misma tesis, en STS 113/2005, y STS 23/2009). 
Veamos, pues, algunas contradicciones. Posiblemente el delito fiscal y el blanqueo sean los conceptos que peor se acomodan mutuamente, pero sin olvidar que no se han de confundir problemas diferentes: la persecución del fraude fiscal se produce sin necesidad de llegar a hablar de dinero procedente de corrupción, por lo tanto, mejor no mezclar lo que es diferente.

El dinero que genera la corrupción está abocado al blanqueo, como es lógico. Ese dinero no difiere del que procede de otras clases de delitos, y, por lo tanto, puede ir a la creación de empresas o, simplemente, quedar a buen recaudo en cualquier banco de los países llamados "paraísos". Ese hecho puede ser descubierto directamente, por el éxito de la pesquisa policial o por otro motivo o ser detectado con ocasión de una inversión en España. Es entonces cuando entraría el juego del delito de blanqueo en concurso con los delitos de corrupción que se hubieran cometido.

A su vez, los hechos de blanqueo pueden ser los de "autoblanqueo" (el "corrupto" intenta invertir el dinero obtenido con la corrupción) o blanqueo genuino, que es el que comete quien ayuda a otro a blanquear. Ya dije antes que la regulación del blanqueo está condicionada por los acuerdos supranacionales (Convenciones de Viena, Palermo y Mérida, y Convenio de Varsovia), y, por lo tanto, la redacción de la figura es una consecuencia directa de esos acuerdos.

En opinión de muchos, se hubiera podido dar cumplimiento a todos esos compromisos internacionales sin necesidad de entrar en una casuística reiterativa de modalidades diferentes de blanqueo. Una norma amplia, centrada en la ayuda a ocultar o diluir el origen delictivo de un dinero hubiera bastado. Pero no fue ese el criterio del legislador español, que debió pensar que la única manera de alcanzar a todas las modalidades de blanqueo era la tipificación expresa de todas y cada una de ellas, sin reparar en que, de esa manera, se corría el riesgo de extender el delito hasta situaciones que nada tienen que ver con la lucha internacional contra el blanqueo. 
La consecuencia la sabemos: una ley penal que castiga una larga relación de conductas supuestamente distintas y con claros perfiles diferenciadores: adquirir, poseer, utilizar, convertir o transmitir, realizar actos orientados a ocultar el origen ilícito de bienes o de ayuda a la persona que ha realizado la infracción, ocultar o encubrir la verdadera naturaleza, origen, ubicación, destino, movimiento o derechos sobre los bienes o propiedad de los mismos, a sabiendas de su delictiva procedencia. Se trata, y es fácil verlo, de una abigarrada descripción de posibles conductas que hubieran podido reunirse en una descripción unitaria que primara la orientación de la conducta a la evitación de que se detectara el origen de los bienes ${ }^{9}$.

No ha sido así, y esa es una de las causas de los desatinos que pueden producirse.

\subsection{Posesión, auto-blanqueo, prescripción y lucha contra la corrupción}

Posiblemente, las decisiones más desafortunadas en la configuración del delito de blanqueo en el derecho español son, desde la Reforma operada por la LO 5/2010, la incriminación de la posesión, tenencia o utilización de bienes, sabiendo que éstos tienen su origen en una actividad delictiva, cometida por él o por terceras personas... De esa manera se introdujo la posesión como situación típica de blanqueo, y, se amplió la esfera de la autoría a los propios responsables del delito generador de los bienes. Así quedaba abierta la posibilidad de que cometa blanqueo el funcionario corrupto que aceptó, como precio del cohecho, entre otras cosas, una obra de arte, de lícita procedencia, al margen de

9 Muchas de las conductas enumeradas en el art.301-1 CP se superponen y podrían resumirse en una sola descripción de las conductas de ocultación, aunque en la práctica se invoquen sin conexión con fines específicos. En cualquier caso, es claro que en este precepto se reúnen comportamientos que de no estar incluidos en el art.301 CP se tipificarían como casos de receptación o de encubrimiento personal o real. Por eso es esencial no perder de vista la meta final, que siempre será la misma: conseguir que bienes de origen ilícito puedan ingresar en los circuitos económicos normales sin que se pueda detectar su origen y naturaleza, o ayudar a los que se dediquen a ello a que lo consigan. 
que pudiera ser decomisada, que exhibe en su domicilio, razón por la cual estará cometiendo un delito permanente de blanqueo durante todo el tiempo que esté en su poder (dejemos de lado, por un momento, la cuestión de la prescripción ), y lo mismo se puede decir del que roba una joya y la conserva, o el que guarda en el banco el producto de la estafa que ha cometido.

La consecuencia sería, inevitablemente, que a todos los delitos patrimoniales les tendría que seguir, casi necesariamente, la calificación adicional de blanqueo, lo cual solo serviría para aumentar la pena, violentando claramente la regla non bis in ídem. La jurisprudencia está comenzando a limitar alguna de las interpretaciones más descabelladas de estos tipos. Así, la STS 29/04/2015, ha advertido que la mera tenencia o la utilización de fondos ilícitos en gastos ordinarios de consumo no constituye autoblanqueo pues no se trata de actos realizados con la finalidad $u$ objeto de ocultar o encubrir bienes, para integrarlos en el sistema económico, añadiendo, y también ha señalado que es preciso realizar una interpretación precisa de la conducta típica sancionada como delito de blanqueo, pues una interpretación excesivamente laxa de la acción típica conduce a resultados que en los casos de autoblanqueo pueden ser vulneradores del principio non bis in idem.

Aun siendo loable ese intento de limitar el alcance del autoblanqueo, no es suficiente, pues en los casos en los que el autor de un delito patrimonial realmente desee esconder los frutos de su delito, según el criterio jurisprudencial apuntado, sí habrá que apreciar un segundo delito, pues es indudable la finalidad de ocultar o encubrir bienes, lo cual conduce a la absurda conclusión antes señalada. Para medir el tamaño del dislate basta con comparar la situación con la que se daría si la ley penal, siguiendo un criterio análogo, ampliara el ámbito de autores del delito de encubrimiento o favorecimiento personal del art.451 $\mathrm{CP}$, incluyendo a los autores y partícipes en el delito cometido. De ese modo resultaría tipificado el "auto-encubrimiento", delito en que incurriría todo responsable penal que huyera o se escondiera, y no solo quien le ayudara a hacerlo. 
A todo esto, debe añadirse que, además, las conductas de utilización, tenencia y posesión habrán de adaptarse a otras consecuencias ${ }^{10}$.Si se llegara a admitir la permanencia penal de la situación de tenencia se llegaría a la enormidad de aceptar un delito que sería imprescriptible, como si se tratara del genocidio.

La jurisprudencia ya ha dicho que esa conclusión no es admisible y, así, en STS 707/2006 de 26 de junio (anterior a la Reforma de 2010) se dice que "...la conversión o transformación del capital para encubrir su origen, operación en que consiste básicamente el blanqueo de capitales, una vez verificada, por ejemplo, a través de la compra de un inmueble, tendría una vocación de permanencia dificilmente conciliable con el instituto de la prescripción. En el delito de blanqueo de capitales se toma para la prescripción la última transformación conocida del dinero procedente del narcotráfico pues no es un delito permanente...".

El problema es que la modalidad de tenencia o posesión no está marcada por un acto de adquisición o transmisión, $\mathrm{y}$, así las cosas, la única solución es calcular el plazo prescriptivo del autoblanqueo a partir del día en que se entró en posesión tenencia del bien, pues la otra interpretación -calcular el inicio del plazo prescriptivo a partir del día en que prescribió el delito principal- lleva a conclusiones inadmisibles si se compara con lo que ha declarado la jurisprudencia, como hemos visto en la sentencia antes citada. Además, cuando se trate de la prescripción del blanqueo cometido por tercero se aplicará el criterio jurisprudencial y, por lo tanto, el plazo correrá a partir del momento de la adquisición del bien, aunque el delito principal no haya prescrito. Aplicar un criterio diferente para el autoblanqueo no sería equitativo.

10 Sin olvidar, otro aspecto de la cuestión, de menor importancia en apariencia, es que esos bienes pueden ser objeto de comiso, de tal manera que la condición de decomisable se añadiría a la de propiciar una calificación penal (consecuencia accesoria del art.127 CP) que se añadiría a la doble incriminación. A este punto volveré más adelante. 
Por supuesto que no olvido que en algunos casos concretos (autoblanqueo con delito fiscal previo) precisamente la tesis dominante es que el autoblanqueo se aprecia porque ha prescrito el delito fiscal. Pero, por una parte, seguir un criterio para el delito fiscal y otro para los demás delitos, no parece correcto, y, por otra, la posibilidad de que el blanqueo cometido por terceros pueda prescribir con independencia de la prescripción del delito principal, y no así el autoblanqueo, no parece aceptable.

Me he referido repetidamente a la cuestión de la prescripción del delito originario, y si ésta determina la exclusión de la tipicidad del subsiguiente blanqueo. De la ley no puede extraerse ninguna solución clara, pero hay que tener en cuenta que el "espíritu de la ley" es poder perseguir a los autores de delitos más allá, en tiempo y en concepto, de lo que permite la estricta figura del delito previo cometido. Como acabo de decir, en cambio, la situación puede ser diferente para los "terceros blanqueadores".

La idea de que la posible tipicidad del autoblanqueo presupone la prescripción del delito previo, ha sido, evidentemente, impuesta por influencia de lo que se quiere defender para el delito fiscal: el empeño en considerar que el delito fiscal puede ser el antecedente del delito de blanqueo cometido por el defraudador tributario obedece, aunque no se diga expresamente, para contar con un armamento subsidiario en el caso de que no hubiera sido posible castigar el delito fiscal por prescripción.

Por lo tanto, el "posicionamiento interpretativo" de partida tendría que ser favorable a separar la tipicidad y perseguibilidad del blanqueo por posesión, tenencia o uso de la prescripción del delito cometido por el propio tenedor, poseedor o usuario, o por otra persona. Pero, en tal caso, no tiene sentido perseguir el autoblanqueo, pues basta con perseguir el delito principal, con la sola excepción de que se dé la situación prevista en el art.127 ter 1-b) CP (rebeldía del acusado).

Sucede que, con esas ideas sobre la prescripción, podemos llegar a conclusiones absurdas. Quien obtuvo beneficios 
materiales como fruto de su corrupción podrá ser perseguido por blanqueo mientras que en sus manos estén bienes derivados de aquellos hechos, aunque estén prescritos.

Una conclusión" de ese estilo daría al tipo de blanqueo por posesión o tenencia una enorme importancia como arma en la lucha contra la corrupción y los corruptos. Pero antes de lanzar campanas al vuelo conviene advertir que en la práctica eso no sería tan fácil:

a) En primer lugar, habría que demostrar que un bien concreto procede de una actividad delictiva asociada a la corrupción. La procedencia del bien puede ser directa o indirecta, lo cual sucederá cuando el bien se haya transformado, como, por ejemplo, cuando el dinero obtenido por corrupción ha sido utilizado para adquirir una casa, en todo $o$ en parte. Al confundirse, en el patrimonio del corrupto, bienes de diferentes procedencias, incluso, alguna, lícita, será difícil sostener que un concreto bien que posee es expresión de un delito de autoblanqueo en modalidad de posesión.

b) En segundo lugar, la condición de bien procedente de delito pasa por una afirmación de carácter normativo: la existencia previa de un delito que generó aquella ganancia. Eso solo lo puede declarar un Tribunal en condiciones de juzgar el hecho, por ser todavía perseguible, pero, en cambio, no podría ser apreciada por otro tribunal, incapacitado para calificar un hecho ya prescrito. Nótese que no me estoy refiriendo a la "prescripción del blanqueo", sino a la prescripción del delito que produjo el bien "blanqueado". Precisamente por eso, es contradictorio que se diga que la inclusión del delito fiscal como delito antecedente del de blanqueo obedeció a la necesidad de evitar las consecuencias de la prescripción de la infracción penal tributaria prolongando la perseguibilidad a través 
del blanqueo ${ }^{11}$, tesis que implica la afirmación de que es posible, en orden a apreciar blanqueo, declarar la existencia de un delito prescrito, a los solos efectos de integrar normativamente un delito presente, dando por sentado que la apreciación de la existencia de un delito no requiere la previa celebración de un proceso penal.

Planteada así la cuestión es fácil llegar a la conclusión de que, en realidad, las modalidades de autoblanqueo presuponen, aunque no se diga en la ley, la imposibilidad de perseguir el delito previo, normalmente por prescripción, pues, si es posible perseguir el delito de corrupción, resulta mucho más lógico $y$ obligado, perseguir ese delito, decomisando los bienes y ganancias que haya podido producir. Esa es una consecuencia lógica de la posición secundaria del autoblanqueo ${ }^{12}$, y la única alternativa interpretativa que se ofrece conduce al absurdo, esto es: que un mismo sujeto pueda ser acusado de un delito y de blanqueo de los bienes procedentes de ese delito, como, por ejemplo, el atracador de una joyería que, en cuanto ha consumado el delito llevándose las joyas, incurriría en un segundo delito de autoblanqueo por posesión de bienes procedentes de delito.

Por lo tanto, hay que aceptar que será precisa una "apreciación de existencia de delito" aunque ese delito no pueda perseguirse. Eso puede parecer lógico, y, como hemos visto, en relación con el delito fiscal, se ha dicho expresamente, pero no deja de ser un planteamiento que tiene "agujeros negros". Declarar que hubo un delito, aunque no se pudo perseguir, exige afirmar

11 Expresamente dice L. Sánchez Seco: “...1a primera gran utilidad del blanqueo de capitales sería el de servir de instrumento para castigar conductas prescritas para el delito fiscal...", en "Blanqueo de capitales. Motivos que justifican la existencia de la regulación de prevención del blanqueo de capitales", Cuadernos de Formación, Instituto de Estudios Fiscales, Volumen 19/2015, p.193. Por demás, la afirmación está cargada de sentido práctico: si el delito fiscal no estuviera prescrito no haría falta echar mano del blanqueo.

12 Respecto de las modalidades genuinas de blanqueo de bienes de origen delictivo de otra persona no es posible sostener la misma crítica, pues es perfectamente imaginable una intervención post-consumación del delito, calificable de blanqueo, sin que el delito principal haya prescrito. 
que se cumplió íntegramente una tipicidad, sin causa alguna de justificación o exculpación, y eso se ha de hacer sin un proceso penal que sostenga la afirmación, en el que se haya llegado a una conclusión condenatoria respetando la presunción de inocencia. y que, por lo tanto, basta con una "tipicidad indiciaria", afirmación que, como es lógico, podría dar lugar a un recurso, etc.etc.

Se dirá, claro es, que cuando se investigue un delito de autoblanqueo en la modalidad de tenencia, o posesión, o, incluso, cualquiera otra, la comprobación del elemento típico "delito previo", se hará exclusivamente a los efectos de apreciar el blanqueo, pero esa limitación del objetivo no puede ocultar la realidad: que se somete a valoración penal un hecho prescrito ${ }^{13}$.

La jurisprudencia, ciertamente, ha declarado (STS 1704/2001 de 29 de septiembre) que para la apreciación del delito de blanqueo de capitales no se exige la previa condena por el delito del que proceden los bienes que se ocultan. Tampoco es preciso que se concrete quiénes han sido los autores y los partícipes, bastando la existencia probada de una actividad delictiva (STS 145/2008, de 8 de abril), o, según otros fallos, la identificación de cuáles eran los delitos previos de los que proceden los bienes, incluyendo la prueba sobre su existencia. Pero todas esas condiciones solo pueden cumplirse en el marco de un proceso penal, que se debió producir y que no puede ser sustituido por una apreciación retrospectiva ${ }^{14}$, que, referida a conductas de corrupción, requieren de una compleja labor de investigación, sin la cual es muy difícil afirmar que lo que posee una persona proviene de actos de corrupción.

13 No se pueden compartir las reaccionarias tesis que ven en la prescripción una especie de vía para escapar de la justicia.

14 El problema va más allá del delito de blanqueo. El TS se ha pronunciado, por ejemplo, en relación con el delito de presentación en juicio de documentos falsos (así en S. 1009/2009, de 14 de octubre de 2009), acerca de la necesidad de que la falsedad previa sea perseguible. En el caso que analiza la citada sentencia, estima que no hubo falsedad sino auto-encubrimiento impune, pero no niega que sea posible exigir que el delito falsario previo no esté prescrito. 
Por otra parte, si se admite, y parece inevitable, que en el autoblanqueo se abre la puerta a que el delito generador de bienes esté prescrito, habrá que decidir también sobre cuánto tiempo de prescrito puede ser admitido sin lesionar elementales exigencias de seguridad jurídica. Pero lo cierto es que, admitido que no importa que el delito previo haya prescrito, no hay modo técnico de establecer un término máximo para la persecución del autoblanqueo.

Se puede esperar una "solución" inspirada en la proporcionalidad, pero, sea cual sea, será, sin duda, incompatible con la certeza del derecho, pero, si se estima que el autoblanqueo no puede ser un delito imprescriptible, y que, de acuerdo con la pena imponible, tendrá un plazo prescriptivo (diez años), habrá que señalar como día a quo para el cómputo de su propio plazo prescriptivo el día en que se produjo la prescripción del delito previo.

Es fácil, en suma, comprender por qué son muchas las opiniones críticas referentes al autoblanqueo y los criterios con los que puede ser aplicado. Frente a esas críticas se defiende que, en todo caso, eso es lo que se deriva de los mandatos supranacionales y que estos han de cumplirse ${ }^{15}$, a lo cual cabe responder que los mandaros se pueden cumplir incorporando solo modalidades de autoblanqueo que no pugnen con la lógica interna del derecho penal.

\subsection{Autoblanqueo y comiso}

La normativa reguladora del comiso y la del autoblanqueo, se "amontonan", y elijo expresamente ese verbo porque es el que mejor refleja la caótica relación entre un delito "consecuencial" como es el autoblanqueo y el comiso de los bienes procedentes del delito, consecuencia accesoria regulada en los

15 Vid. en esa línea: P. Faraldo Cabana, "Antes y después de la tipificación expresa del autoblanqueo de capitales”, en Estudios Penales y Criminológicos, vol. XXXIV, 2014. 
arts. 127 y ss. $\mathrm{CP}^{16}$. Unas y otras normas persiguen, en el fondo, lo mismo, esto es: impedir que ni los autores ni otras personas puedan disfrutar de los bienes y ganancias producidos por delitos, o actividades criminales en sentido amplio.

Pero los bienes que una persona (o un tercero) tenga, y que se pueda presumir proceden de delitos antes cometidos, son también "objeto del autoblanqueo". La procedencia delictiva puede no estar clara, y puede suceder que se mezclen bienes de diferentes naturalezas u orígenes, pero el "aparato legal" que puede dirigirse contra su poseedor resulta variado, y posiblemente contradictorio.

El tema es importante, pues, no se olvide, estamos tratando de instrumentos en la lucha contra la corrupción. Se ha dicho que en esa lucha es importante la figura del blanqueo por posesión, utilización o tenencia, pero la confluencia de normas puede complicar las cosas, puesto que el sujeto corrupto o que fue corrupto, que puede ostentar bienes procedentes de su propia corrupción, podrá verse en una de las siguientes situaciones:

a) Que ya hubiera sido condenado por delitos relativos a la corrupción y que, en esa misma sentencia condenatoria, además, se hubiere acordado el comiso de sus bienes. Si esa es la situación, normalmente no habrá espacio para la comisión de autoblanqueo, salvo el caso de que, por el modo que fuera, el condenado hubiese logrado esconder parte de sus bienes.

b) Que no hubiera sido previamente condenado, la cual será la situación más frecuente en casos de autoblanqueo, pues, como en su momento advertí, la explicación más común de la acusación de blanqueo pasa por la imposibilidad de perseguir el prescrito delito

16 El art.127 bis ofrece una relación de delitos, que pueden entrar en el ámbito del comiso, pero es tan larga que prácticamente equivale a incluir cualquier delito capaz de generar ganancias, y, por supuesto, todos los relativos a la corrupción. 
principal, sin perjuicio de que en España el MF, como dije al principio, añada sistemáticamente la calificación de blanqueo en todos los escritos de calificación sobre hechos, prescritos o no, en los que haya habido ganancias, como si de una fórmula de estilo se tratara. El proceso penal por autoblanqueo podrá concluir con sentencia condenatoria y subsiguiente decomiso. También puede suceder que se acuerde el comiso en ausencia, de acuerdo con lo establecido en el artículo 127 ter CP, pero esa es otra cuestión.

Así las cosas, tenemos que la tenencia de bienes procedentes de delito puede dar lugar a la acusación de blanqueo y al comiso de los mismos, y si esos bienes están poder de terceros, también podrán ser decomisados, conforme a lo dispuesto en el art.127 quater mediante un procedimiento especial e independiente de comiso. Pero si se repara en lo que establece el art.127 quater ${ }^{17}$, resulta realmente difícil que ese tenedor o poseedor no vaya a ser acusado también de blanqueo, si realmente conoció el origen de los bienes y que ayudaba a evitar que fueran decomisados. Lo que, en todo caso, sería difícilmente admisible es que también en estos supuestos el "procedimiento autónomo de comiso" se previera para aquellos casos en los que el tercero poseedor ya no pudiera ser acusado de blanqueo.

17 1. Los jueces y tribunales podrán acordar también el decomiso de los bienes, efectos y ganancias a que se refieren los artículos anteriores que hayan sido transferidos a terceras personas, o de un valor equivalente a los mismos, en los siguientes casos: a) En el caso de los efectos y ganancias, cuando los hubieran adquirido con conocimiento de que proceden de una actividad ilicita o cuando una persona diligente habría tenido motivos para sospechar, en las circunstancias del caso, de su origen ilícito. b) En el caso de otros bienes, cuando los hubieran adquirido con conocimiento de que de este modo se dificultaba su decomiso o cuando una persona diligente habría tenido motivos para sospechar, en las circunstancias del caso, que de ese modo se dificultaba su decomiso. 2. Se presumirá, salvo prueba en contrario, que el tercero ha conocido o ha tenido motivos para sospechar que se trataba de bienes procedentes de una actividad ilícita o que eran transferidos para evitar su decomiso, cuando los bienes o efectos le hubieran sido transferidos a título gratuito o por un precio inferior al real de mercado. 
Es cierto que uno y otro tienen diferente naturaleza (delito y consecuencia accesoria), pero también es cierto que la consecuencia accesoria de comiso tiene una carga represiva que no se puede menospreciar.

Por otra parte, el comiso puede extenderse a bienes sobre los que concurran derechos de terceras personas, ajenas al delito, que están disfrutando de esos bienes y su derecho no puede ser lesionado. Pero todo se complica con la concurrencia del delito de blanqueo por mera tenencia o posesión, pues, tanto si los bienes están en poder de alguien relacionado con la comisión del delito, como si están en poder de un tercero del cual se pueda afirmar que conoció o pudo suponer el origen de esos bienes, antes que acordar el comiso, en nombre del delito "originario", será posible calificar penalmente el hecho como blanqueo, ya sea "autoblanqueo" o blanqueo ordinario por tenencia de bienes de un tercero pero de origen delictivo, en cuyo caso los bienes tendrán que seguir el destino que les dé una sentencia condenatoria. $^{18}$

\subsection{Autoblanqueo y terceras personas}

De los muchos problemas que genera la desafortunada figura del autoblanqueo elegiré, para cerrar estas páginas, solo algunos. Sin duda que el volumen mayor de ellos se ubica en el delito fiscal "no juzgado" que se pueda considerar antecedente en

18 Para completar el panorama de acumulación o superposición de normas hay que recordar el artículo $122 \mathrm{CP}$ que regula la participación a título lucrativo, también llamada receptación civil, y alcanza a quienes estén disfrutando de bienes procedentes de delito a título gratuito, respecto de los cuales se puede ordenar la restitución, y, además, podrá defenderse que ésta alcanza a las ganancias procedentes de delitos cualquiera que sea la transformación que haya sufrido (art.127-1 CP), pues lo que rige sobre el alcance del comiso tendrá que ser válido también para la receptación civil. Si es así, podrá suceder que la vivienda adquirida por el autor del delito y pagada con las ganancias obtenidas, y en la que reside su familia pero no él mismo, podrá ser decomisada. Las consecuencias que esa posibilidad abre pueden ser preocupantes, pero es evidente que las vías son varias: la vía directa de la imputación de blanqueo, la de la receptación civil, y la del comiso. 
orden al autoblanqueo, y en la esfera de ese delito fiscal no juzgado puede entrar cualquier capital de una persona que no hubiera sido declarado en su momento. Afirmar, directamente, que eso es bastante para afirmar la existencia de "delito fiscal previo" es incompatible con la seguridad jurídica constitucionalmente prometida, pues que haya un dinero que no ha tributado no quiere decir que se haya realizado la tipicidad del delito fiscal.

En doctrina se ha dicho (Dopico) que la tendencia a acusar de autoblanqueo obedece a la confusión de funciones entre las que son propias del delito de blanqueo y las que corresponden al comiso. Éste último tiene como prioritaria función impedir el disfrute de las ganancias procedentes de delitos, pero no es esa la función del delito de blanqueo. En cambio, cuando se oyen los argumentos de defensa del autoblanqueo, se entremezclan razonamientos que ponen en evidencia esa confusión de funciones y objetivos.

Un ámbito en donde los despropósitos alcanzan el máximo nivel es el de la relación de terceros con el "auto-blanqueador". En ocasiones se ha sostenido que quienes utilizan bienes de esa persona entran también en el delito de blanqueo, lo cual equivale a afirmar que quien utiliza unas horas el vehículo que ha robado otro y que se lo ha prestado, comete un delito de hurto de uso de vehículo de motor.

\section{Conclusión}

No abrigo duda alguna acerca de la necesidad de perseguir el blanqueo de dinero, pero, en cambio, en lo que se refiere a las modalidades de blanqueo por tenencia o posesión o uso, $y$, especialmente, a las de autoblanqueo, la crítica ha de ser muy severa, pues el sistema penal no ha configurado reglas de interpretación y aplicación por mero capricho, sino por razones de certeza del derecho.

La lucha contra la corrupción requiere de un armamento muy amplio, pero eso no puede llevarse al extremo de corromper el sistema jurídico. 